\title{
A Possible Causal Mechanism of Geomagnetic Variations as Observed Immediately before and after the 2011 Tohoku-Oki Earthquake
}

\author{
Yuji Enomoto1, Kosuke Heki², Tsuneaki Yamabe1, Shigeki Sugiura ${ }^{3}$, Hitoshi Kondo ${ }^{3}$ \\ ${ }^{1}$ Shinshu University, Ueda Campus, Ueda, Japan \\ ${ }^{2}$ Department of Natural History Science, Hokkaido University, Sapporo, Japan \\ ${ }^{3}$ Genesis Research Institute, Inc., Nagoya, Japan \\ Email: enomoto@shinshu-u.ac.jp
}

How to cite this paper: Enomoto, Y., Heki, K., Yamabe, T., Sugiura, S. and Kondo, H. (2020) A Possible Causal Mechanism of Geomagnetic Variations as Observed Immediately before and after the 2011 Tohoku-Oki Earthquake. Open Journal of Earthquake Research, 9, 33-49.

https://doi.org/10.4236/ojer.2020.92003

Received: January 22, 2020

Accepted: March 7, 2020

Published: March 10, 2020

Copyright $\odot 2020$ by author(s) and Scientific Research Publishing Inc. This work is licensed under the Creative Commons Attribution International License (CC BY 4.0).

http://creativecommons.org/licenses/by/4.0/

\begin{abstract}
During the Mw9 Tohoku-Oki earthquake, gradual increases in both ionosphere total electron content (TEC) and geomagnetic declination signals were observed, starting from $\sim 40$ minutes before the mainshock, followed by impulsive enhancements $\sim 10$ minutes after the mainshock. There have been many studies on pre-seismic TEC enhancements, including their characteristics, debates regarding whether TEC anomalies are real signals or artefacts, and the explainable models, and many studies have reported that the impulsive TEC enhancement was caused by a tsunami-induced neutral atmospheric gravity wave. Since TEC and geomagnetic declination anomalies were synchronized so that their origin should be attributed to the same seismic activities, any models must explain both anomalous phenomena, but not the case considered herein. Compared with the corresponding TEC anomalies, we re-examined the characteristics of geomagnetic variation just before and after the mainshock, focusing on the generation process of the impulsive enhancement immediately after the mainshock. We showed that the observed anomaly could be explained if there are quasi-static electric currents of $20-30 \mathrm{kA}$ generated near the epicentre area. The possible mechanism of the current generation is discussed in terms of the ionization process in the atmosphere near the sea surface.
\end{abstract}

\section{Keywords}

Tohoku-Oki Earthquake, Geomagnetic Declination, TEC, Blanchard Effect, Tornado-Like Cloud

\section{Introduction}

Whether detectable pre-seismic or pre-tsunamigenic anomalies exist and what 
methods, if any, can be used to identify precursor signals are of considerable concern from the viewpoint of active disaster prevention. Such a case occurred for the $2011 \mathrm{M}_{\mathrm{w}} 9.0$ Tohoku-Oki earthquake; that is, anomalous ionospheric disturbances that appeared above the rupture zone immediately before and after the mainshock were revealed by high-resolution GPS total electron content (TEC) observation. Gradual positive TEC increases started from $~ 40$ minutes before the mainshock [1], which followed the tsunamigenic impulsive TEC enhancement above the ionospheric epicentre $\sim 10$ minutes after the shock. Then, concentric waves appeared to propagate in the radial direction [2] [3], leaving a tsunami ionospheric hole around the ionospheric epicentre [4] [5].

Note that synchronous with change in the ionospheric TEC signals, a similar anomaly appeared in geomagnetic declination change $(\Delta \mathrm{D})$; i.e., preseismic positive (eastward) increases starting from $\sim 40$ minutes before the mainshock up to $\sim 0.4$ arcmin at stations closer to the epicentre, followed by an impulsive $\Delta \mathrm{D}$ increase $\sim 10$ minutes after the mainshock [6], although whether the $\Delta \mathrm{D}$ anomalies were due to a space ionospheric magnetic storm [7] or a pre-seismic activity [8] is still being discussed. We believed that both the pre-seismic anomalies in TEC and $\Delta \mathrm{D}$ satisfy the validation criteria in the "guidelines for the submission of earthquake precursor candidates" presented by Wyss [9], except for an understanding of the underlying causal mechanism [6] [10].

As for the possible mechanism, recent investigations based on an increase in our understanding of pre-seismic TEC anomalies have addressed how lithospheric processes drive ionospheric disturbances via lithosphere-atmosphereionosphere (LAI) coupling. These models involve radon emanations, which would increase the conductivity of the atmosphere [11] [12]; excitation of atmospheric oscillations, i.e., atmospheric gravity waves, due to precursory changes of ground surface, which results in upward propagation [13]; magnetic induction coupling due to telluric currents driven by coupled interaction of quasi-static rupture of the earthquake nuclei with the deep Earth gases [14]; the ionospheric perturbation due to the global electric current between the bottom of the ionosphere and the ground surface [15], where the stressed rock at depth activates hole charge carriers and is driven upward [16]; and $\mathbf{E} \times \mathbf{B}$ drift caused by the interaction of the electric field $\mathbf{E}$ produced in the ionosphere by the generation of positive charge at the ground surface due to stress with the magnetic field in the ionosphere B [17]. Note that fewer coseismic TEC variations occurred at the time of the earthquake, 05:46 UT, even as a stress drop as high as $30 \mathrm{MPa}$ occurred around the hypocentre region [18] [19], suggesting that these phenomena cannot be simply explained by stress-activation mechanisms. Any models have to provide a plausible explanation for both the observed precursor TEC and the $\Delta \mathrm{D}$ anomalies. These phenomena remain largely unexplained.

On the other hand, the impulsive TEC enhancement appeared $\sim 10$ minutes after the mainshock, and the depletion in ionosphere TEC variations that followed has been explained in terms of a neutral atmospheric/acoustic gravity 
wave in the atmosphere induced by tsunami uplift motion [20]. This model has been supported by many researchers; e.g. [1] [2] [3] [4] [21] [22]. Note that the tsunami generated by the 2011 Tohoku-Oki earthquake was characterized by two phases: a long period sea level change and a subsequent short-period impulsive wave [23]. The source of the former was the vertical displacement of the sea floor due to the earthquake, whereas that of the latter was most likely submarine mass failure, i.e., submarine landslide [24]. In the previous studies, which of the two types of tsunami was involved in the formation of TEC impulses is unclear. Furthermore, how the generation of the electrically neutral acoustic wave is related to geomagnetic declination anomalies that were simultaneously observed with ionospheric TEC variations remains unexplained. Therefore, in order to clarify some of these uncertainties, we re-examined the spatiotemporal geomagnetic variations, observed at various sites located throughout Japan, before and after the 2011 Tohoku-Oki earthquake, referencing the corresponding ionospheric vertical TEC (VTEC) variations.

\section{Data}

The geomagnetic data on March 11 when the 2011 Tohoku-Oki earthquake occurred were obtained from 15 Japanese geomagnetic observatories as shown in Figure 1(a). The sampling interval of these data is 1 minute. In order to correct the effect of geomagnetic variations of external origin, the geomagnetic data obtained from KNY, which is located about $1300 \mathrm{~km}$ distant from the epicentre, was chosen as a reference. We denote the difference between the geomagnetic declination D at ESA and that at KNY as $\triangle \mathrm{D}$. The corresponding ionospheric VTEC data used to compare with the geomagnetic data are reported elsewhere in detail [6].

\section{Results}

\subsection{Geomagnetic Observations}

Figure 1(b) \& Figure 1(c) show the spatiotemporal geomagnetic declination variations $(\Delta \mathrm{Ds})$ during the period of 4:00-8:00 UT on 11 March 2011 at various observation sites relative to KNY arranged in descending order of proximity to the epicentre. The background levels, shown by red lines, were determined by fitting with quartic functions during the time period of 4:00-8:00 UT, except for 5:00-6:00 UT, when seismic disturbances occurred. The results showed that the pre-seismic $\Delta \mathrm{D}$ increases are larger because they are closer to the epicentre. Among these values, the $\Delta \mathrm{D}$ variation at $\mathrm{MMB}$, the northernmost site as can be seen in Figure 1(a), appears to have fluctuated exceptionally, even outside the time period affected by the earthquake (5:00-6:00), where the signal might be contaminated by an ionospheric magnetic storm (see Appendix A).

Figure 1 (c) shows $\triangle \mathrm{D}$ variations from backgrounds at HAR, ESA, and MIZ compared to KNY, which are located closer to the epicentre. Note that $\Delta \mathrm{D}$ at HAR, which is closest to the epicentre, suddenly decreased during the earthquake. 

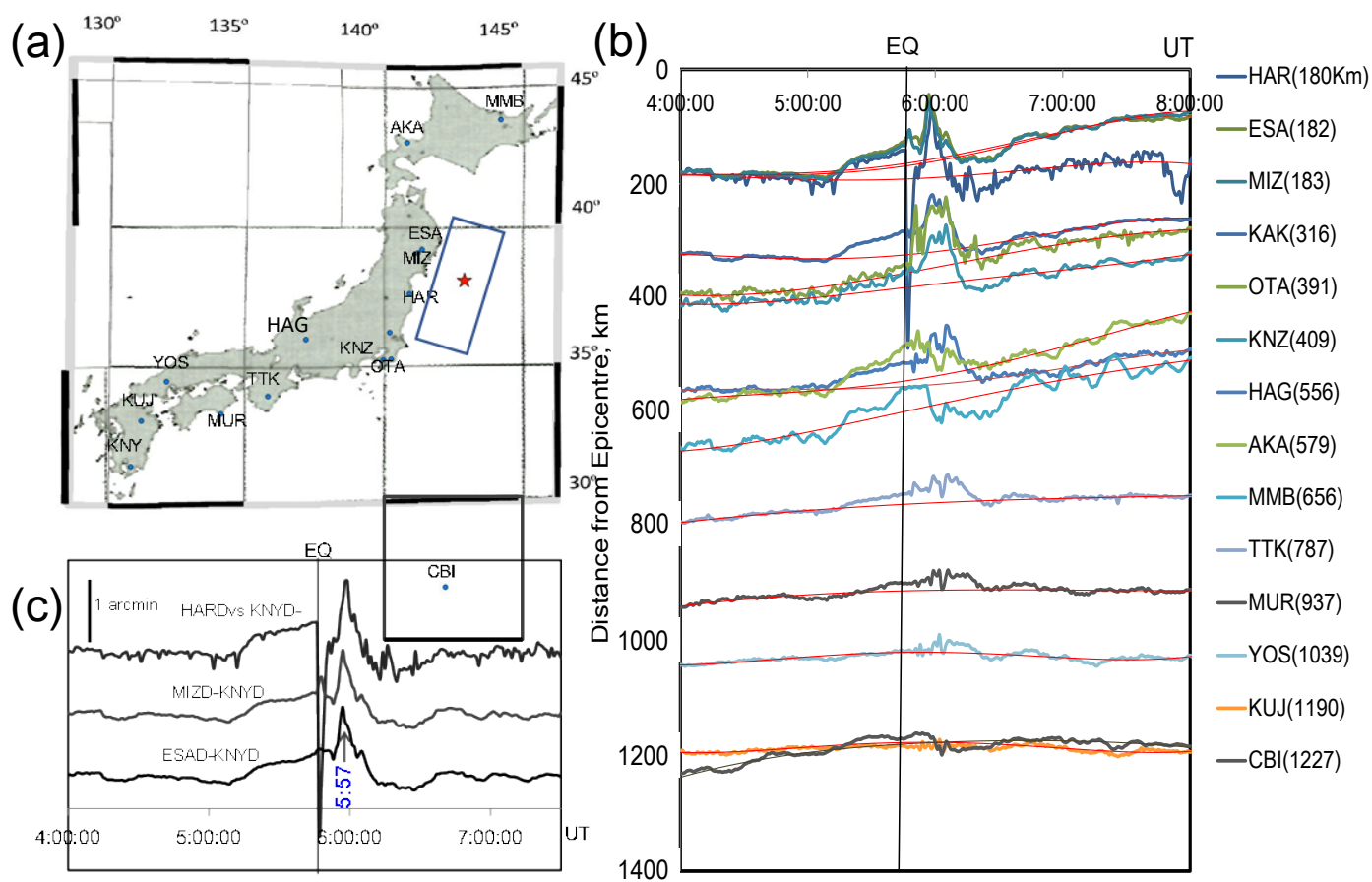

Figure 1. (a) Map of the geo-magnetic observation sites. The rectangle with the solid outline represents the rupture zone, and the red star represents the epicentre of the $M_{w} 9$ mainshock. (b) Spatiotemporal $\Delta D$ variations at various observation sites relative to KNY during the period of 4:00-8:00 UT on 11 March 2011 arranged in descending order of proximity to the epicentre. The numbers in the vertical axis and the parentheses on the right-hand side are the distances in kilometres from the epicentre to the observation sites. The background levels shown by the red lines are determined by fitting with quartic functions during the time period of 4:00-8:00 UT, except for the seismically disturbed period of 5:00-6:00 UT. (c) The $\Delta \mathrm{D}$ variations from background at HAR, ESA, and MIZ, which were located closer to the epicentre, as compared to KNY. The sudden decrease at HAR as compared to KNY at the time of the earthquake should be attributed to the sensor being shaken by the seismic vibration. The maximum height of the impulse $\Delta \mathrm{D}$ from the background is denoted as $\Delta \mathrm{D}_{\mathrm{p}}$.

This is thought to be due to the sensor being shaken by the seismic vibration [25]. These are well-highlighted phenomena, whereby the gradual eastward preseismic increases in $\Delta \mathrm{D}$ were started from $\sim 40$ minutes until the mainshock at 5:46 UT, and the amount of variation of $\Delta \mathrm{D}$ values from the background reached 0.4 arcmin at the time 1 minute before the earthquake occurrence. Then, without any notable coseismic change in the $\Delta \mathrm{D}$ signal, immediately after the mainshock, the impulsive $\Delta \mathrm{D}$ signal suddenly increased from 5:53 UT, reaching a maximum of as high as 0.6 arcmin at 5:57 UT, and then suddenly decreased. Since the $\Delta \mathrm{D}$ signal at HAR shows irregular noise, even outside the period of seismic disturbance of 5:00-6:00 UT, we used the geomagnetic data at ESA or MIZ to examine the characteristics just before and after the mainshock in detail.

Figure 2 shows $\Delta \mathrm{D}$ and the $\Delta \mathrm{H}$ (horizontal) and $\Delta \mathrm{Z}$ (vertical) components at ESA as compared to KNY during 4:30-6:30 UT. The coseismic change at 5:46 UT in $\Delta \mathrm{H}$ and $\Delta \mathrm{Z}$ might be attributed to the sensor being shaken by the seismic vibration, such as that at HAR. Note that when the impulsive $\Delta \mathrm{D}$ increased from 


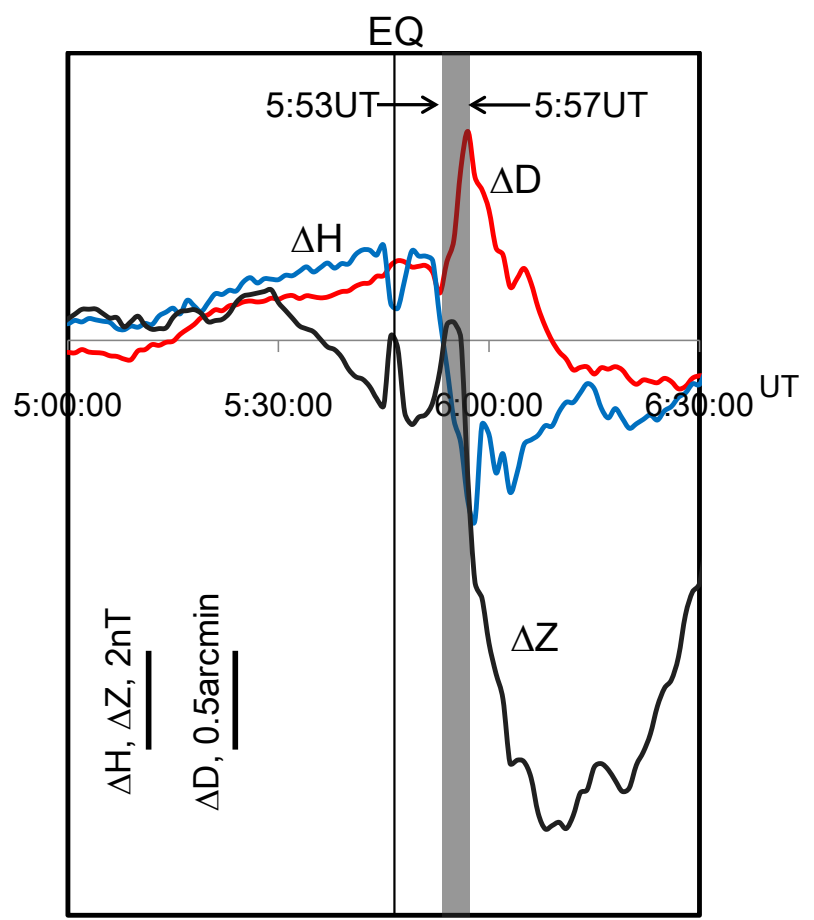

Figure 2. $\Delta \mathrm{D}, \Delta \mathrm{H}$, and $\Delta \mathrm{Z}$ components at ESA as compared to KNY during 4:30-6:30 UT on 11 March 2011.

5:53 UT and then reached a maximum at 5:57 UT, $\Delta \mathrm{H}$ decreased, but $\Delta \mathrm{Z}$ was unchanged. Similar changes were observed at MIZ as compared to KNY. After the impulse, $\Delta \mathrm{D}$ reached a maximum, and the $\Delta \mathrm{Z}$ value then decreased rapidly until 6:11 UT. Note that the arrival time of the first wave of the tsunami at Ofunato (a port town located approximately $50 \mathrm{~km}$ east of ESA) was 15:15 LT (6:16 $\mathrm{UT})$.

\subsection{Ionospheric TEC Observations}

The $\triangle \mathrm{D}$ variations described above were compared to the ionospheric VTEC variations: As shown in Figure 3(a), the VTEC changes for 4:00-7:30 UT observed at six stations with satellite \#26: 940049, 950241, 95072, 950228, 950154, and 95156 . Figure $3(\mathrm{~b})$ shows the trajectories of sub-ionospheric points (SIP) assuming a thin layer at an altitude of $300 \mathrm{~km}$ during 4:00-7:30 UT. The VTEC anomalies that showed clear positive enhancements started from $\sim 40$ minutes before the mainshock [1], at the SIPs above the epicentre and at those above the ESA observation site, but were not clear further north from the north end of the rupture zone. Note that the VTEC anomalies immediately before and after the mainshock for the SIPs closer to the epicentre (950228 and 950272) are similar to the $\triangle \mathrm{D}$ anomaly at ESA as compared to KNY, but this is not the case for the anomalies closer to the ESA observation site; that is, the impulse TECs did not appear in the SIPs above the ESA site. This indicates that the ionospheric variation above the ESA site has less effect on the $\triangle \mathrm{D}$ anomaly observed at the ESA site, which is consistent with the results described in Appendix A. In other 


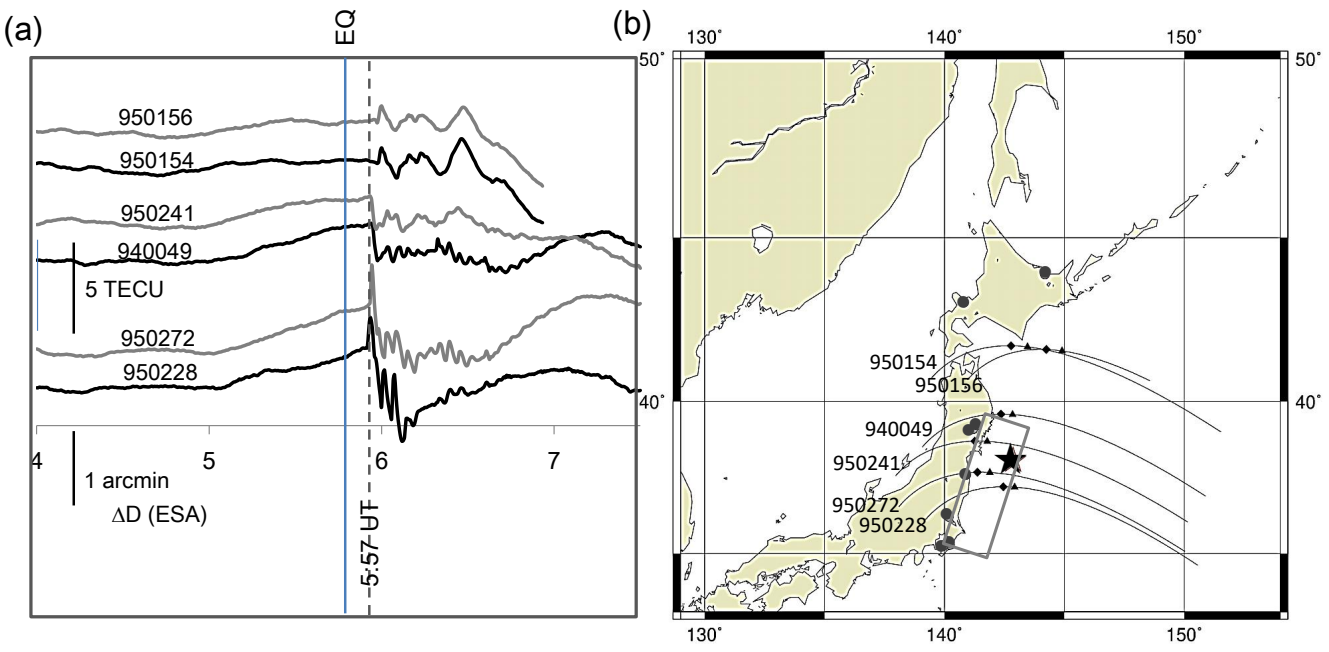

Figure 3. (a) Vertical TEC variations observed during 4:00-7:30 UT 11 on March 2011 at following sites: closer to the epicentre, 950228 and 950272; closer to ESA, 950241 and 940049; and off the north end of the rupture zone, 950154 and 950156. (b) Respective trajectories of sub-ionospheric points (SIPs) assuming a thin layer at an altitude of $300 \mathrm{~km}$ (grey lines). The rectangle with the solid outline represents the rupture zone, and the black star represents the epicentre of the $\mathrm{M}_{\mathrm{w}} 9$ mainshock. The symbols on the SIPs indicate points at which the earthquake occurred, and the $\Delta$ symbols indicate points at which the impulse TEC peak appeared. Black circles indicate the geomagnetic observation site in the northern area of Japan. (cf. Figure $1(\mathrm{c})$ ). $\triangle \mathrm{D}$ at ESA (blue curve) is also shown in Figure 1(a) for comparison.

words, both VTEC and $\triangle \mathrm{D}$ anomalies during the period of 5:00-6:00 UT were not affected by an ionospheric magnetic storm. Furthermore, note that the peak time of the impulsive $\triangle \mathrm{D}$ signal at ESA is 5:57 UT, which agrees exactly with that of the impulsive VTEC signal.

Then, $\sim 10$ minutes after the mainshock (5:57 UT), impulsive enhancements as high as $\sim 3$ TEC units ( 1 TEC unit is $10^{16}$ electron $/ \mathrm{m}^{2}$ ) appeared, as shown in Figure 3(a) for SIPs for 950228 and 950272 (Figure 3(b)), followed by a sudden depletion at approximately 6:00 UT. According to Saito et al. [2] and Tsugawa et al. [3], concentric waves appeared to propagate in the radial direction with a velocity of 138 to $3457 \mathrm{~m} / \mathrm{s}$ after impulsive TEC enhancement appeared at the ionospheric epicentre.

In addition, an impulsive VTEC peak at 950272 appeared at 6:00 UT, which is 3 minutes after the peak time at 950228 , at which the propagation velocity is estimated as $2828 \mathrm{~m} / \mathrm{s}$, which agrees with the velocity range determined by Tsugawa et al. [3].

\section{Discussion and Summary}

In light of the above results, we re-confirmed that the $\triangle \mathrm{D}$ variations at ESA and MIZ as compared to KNY during 5:00-6:00 UT, immediately before and after the mainshock, were not originated by the ionospheric magnetic storm, but presumably by seismic activities near the epicentre.

Next, we consider the precursor geomagnetic variation during 5:06-5:46 UT. 
Thus far, geomagnetic variation associated with the earthquake has been explained either as a result of the stress-induced piezo effect: e.g. [26] [27] or that of a magnetic field generated due to an electric current, as given by the Biot-Savart law: e.g. [28] [29]. The coseismic electromagnetic change due to the piezomagnetic effect around the outer edge of the rupture zone in the 2011 Tohoku-Oki earthquake, as theoretically estimated by Utada et al. [22], is at most 1 $\mathrm{nT}$ at the outer edge of the rupture zone and should be much smaller at ESA, which is $70 \mathrm{~km}$ from the outer edge of the rupture zone. Therefore, the piezomagnetic effect could not explain the observed $|\mathrm{H}|$ variation of $\sim 2 \mathrm{nT}$ at ESA. The magnetic field change at ESA should therefore be attributed to electric current generation.

Next, we investigate the electric current source. In order to investigate the possible source mechanism of the electric current, we consider the most prominent geomagnetic variation of the impulse signals of $\Delta \mathrm{D}$ (hereafter noted as $\Delta \mathrm{D}_{\mathrm{p}}$ ), the peak time of which (5:57 UT) agreed with that of the VTEC near the epicentre. The matching of the occurrence time between the impulse $\Delta \mathrm{D}_{\mathrm{p}}$ at ESA and the impulse VTEC at the ionospheric epicentre suggests that the electric current should be generated during the process in association with the ionospheric epicentre formation. The results, as shown in Figure 2, that the impulsive $\Delta \mathrm{D}$ increased from 5:53 UT to a maximum at 5:57 UT, while $\Delta \mathrm{H}$ decreased, but $\Delta \mathrm{Z}$ was unchanged, could be explained if we assume that the acoustic gravity wave was accompanied by tsunami-carried positively charged particles. In other words, a transient electric current flowed upward from the ocean around the epicentral area to the lower ionosphere during the period of 5:53-5:57 UT, where the current induced the counterclockwise magnetic field to reduce the $|\mathrm{H}|$ component and increase the declination, but did not change the $|Z|$ component at ESA or MIZ as compared to KNY (see Figure 4(a)).

(a)

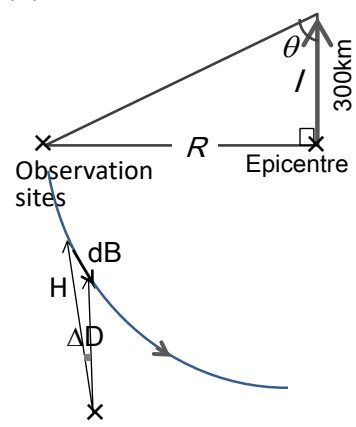

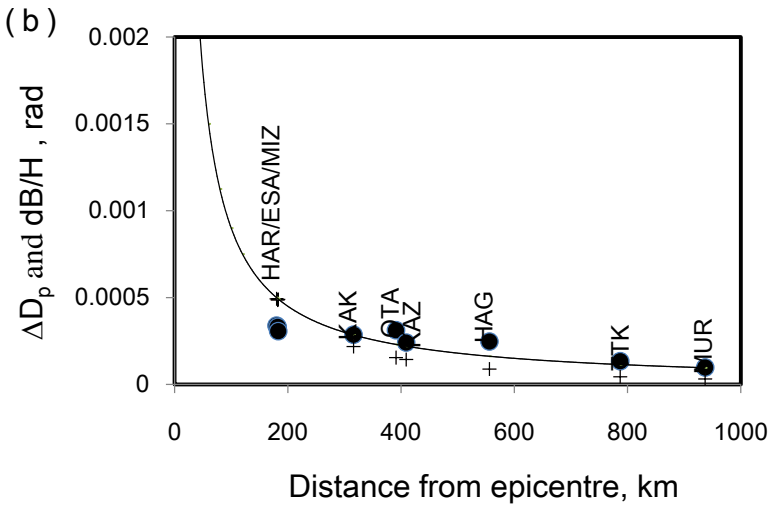

Figure 4. (a) Geometric illustration with an assumed line current flowed upward from epicentre, and relationship between $\Delta \mathrm{D}, \mathrm{H}$ and $\mathrm{dB}$. (b) The impulse $\Delta \mathrm{D}$ peaks at various sites observed at 05:58 UT are indicated by $\bullet$ symbols, and those estimated from Equation (1) and Equation (2) using the $|\mathrm{H}|$ values at each site averaged for 5 min before 5:46 UT, when the seismic anomalies started, are indicated by + symbols. The solid line represents the $1 / R$ relationship approximating the estimated values. 
The reason why acoustic gravity waves are electrically charged will be discussed later. Next, we estimate the current needed in order to explain the impulse $\triangle \mathrm{D}$ at ESA. Assuming simply that a transient line current flowed straight upward from the epicentral ocean area to the lower ionospheric altitude of 300 $\mathrm{km}$, we can estimate geomagnetic field $|\mathrm{dB}|$ induced by current $I$ using the Biot-Savart law:

$$
|\mathrm{d} \mathbf{B}|=\frac{\mu_{0} I}{4 \pi R} \cos \theta
$$

where $\mu_{0}$ is the permittivity of free space $\left(\mu_{0}=4 \pi \times 10^{-7} \mathrm{~Wb} /(\mathrm{Am})\right) . R$ and $\theta$ are shown in Figure 4(a). Using Equation (1), $\Delta \mathrm{D}$ estimated as

$$
\Delta \mathrm{D}[\mathrm{rad}]=|\mathrm{d} \mathbf{B}[\mathrm{nT}] / /| \mathbf{H}[\mathrm{nT}] \mid .
$$

Using ESA's $|\mathrm{H}[\mathrm{nT}]|(=29,001.2 \mathrm{nT})$, the calculated current that matches the observed value of peak value of impulse $\Delta \mathrm{D}$ of $1.134 \mathrm{arcmin}=0.00333 \mathrm{rad}$ from Equation (1) and Equation (2) is estimated as 20,000 A. The diameter of the cross-sectional area of the current is assumed to be $300 \mathrm{~km}$, which is comparable to the size of the ionospheric TEC epicentre, and the current density is estimated as $280 \mathrm{pA} / \mathrm{m}^{2}$, which is approximately 100 times as large as the atmospheric current flowing through fair weather [30].

As shown in Figure 4(b), the peak values of $\Delta D$ including other far observation sites agree with calculated values with a current of 30,000 A, rather than $20,000 \mathrm{~A}$. This is probably because the impulse $\Delta \mathrm{D}$ peak values at KAK, KNZ, and OTA have not decreased much, despite being far from the epicentre. These results are possibly because interlocking of heterogeneous plate coupling extended on southern asperities of the rupture zone [31], so that additional current flows at these areas might influence $\triangle \mathrm{Ds}$ at $\mathrm{KAK}, \mathrm{KNZ}$, and OTA.

Next, we discuss how these currents are generated. In other words, we discuss why charged particles were generated on the sea surface near the epicentre. Note that when the earthquake occurred, a long-period tsunami was generated due to the vertical displacement of the sea floor, and subsequently the short-period impulsive tsunami wave followed due to submarine mass failure, i.e., submarine landslide at a steep cliff near the trench axis [24]. Moreover, note that the impulse tsunami might induce impulsive variation of magnetic field as observed by an ocean-bottom magnetometer (OBEM) placed $50 \mathrm{~km}$ east of the Japan trench [32]. The magnetic impulse might have been induced by the tsunami dynamo effect [33]. The peak time of the magnetic impulses of the $\mathrm{X}, \mathrm{Y}$, and $\mathrm{Z}$ components observed by OBEM was 05:53-05:54 UT, which agreed with the signal rise time of $\triangle \mathrm{D}$ at ESA ( 3 minutes before the peak time of $\left.\Delta \mathrm{D}_{\mathrm{p}}\right)$.

Severe ocean floor motion near the epicentre might have erupted large amounts of biogenic methane bubbles accumulated in the sediment. In fact, the deep-sea submersible "Shinkai 6500" revealed the appearance of fissures and bacterial mats, which were associated with gas ebullition associated with the 2011 Tohoku-Oki earthquake [34]. Methane bubbles uplifted with the move- 
ment of rapid seawater rise along steep slopes near the trench axis and then broke at the sea surface, which resulted in the generation of positively charged mists in air on the sea surface [35] [36]. Another possible primary process is the ionization of the air produced by an increased emanation of radon/other gases from faults in the vicinity of the epicentre [11].

When charged mists flow upward, as a result of the uplift motion driven by an impulsive tsunami, in the atmosphere at the altitude above approximately $1 \mathrm{~km}$, where water vapour in the atmosphere is likely to be in a supersaturated state, a current path is expected to be visualized as a standing cloud formation due to the Wilson's cloud chamber effect [37] (see Appendix B). The cloud is then forced to swirl by hydro-magnetic instability in which the interaction between the current and its magnetic confining field tend to cause kink instability of the current flow. In fact, as reported in the Kahoku-Shimpo newspaper on 13 April 2011 that three well-developed blackened tornado-like clouds standing offshore in the direction of the epicentre were witnessed from the rooftop of a school building in Natori City, located at the sea side approximately $70 \mathrm{~km}$ west of the epicentre, just before the initial tsunami arrival time of 6:01 UT [38] (see the black tirbado-like cloud sketch in

http://memory.ever.jp/tsunami/shogen_natori.html). Since the impulsive increases in both the $\triangle \mathrm{D}$ at ESA and the TEC signals observed at the 950272 site by satellite \#26 started at 5:53 UT and reached a peak at 5:57 UT. These clouds may have developed around the same time period of 5:53-5:57 UT. The eyewitness report might be evidence to support the lithosphere-hydrosphere-atmosphereionosphere (LHAI) coupling model via atmospheric current flow (see also Appendix B).

It is known that thunderstorms act as current generators to drive electric currents upward through the conductive atmosphere toward the ionosphere, propagate outward in the ionosphere, and finally connect to downward currents closing a global electric circuit [30]. Similarly, the electromagnetic anomalies, as observed by geomagnetic and TEC observations that occurred immediately after the 2011 Tohoku-Oki earthquake, could be said to be phenomena related to a global electric circuit formed by the flow of electric charge driven by the impulse tsunami. Tornado-like clouds [33] and the concentric TEC wave propagation [2] [3] are parts of the visualized global electric circuit.

Finally, returning to the precursor phenomena, we will discuss the possible cause of precursor variations in $\triangle \mathrm{D}$ and TEC. From the analysis of GPS data, the crustal displacement in the $\mathrm{E}-\mathrm{W}$ direction has been observed in the coastal area near the epicentre approximately 3 hours before the earthquake [39]. This suggests that the seabed near the epicentre had become unstable due to quasi-static rupture of the earthquake nucleation zone, and therefore bacterial methane gases were likely to be released from the sediments of the seafloor. A video that appeared to have captured a similar phenomenon was captured near the Sanriku coast just after the 2011 Tohoku earthquake (Appendix B). If the phenomenon 
(a)

TEC enhancements

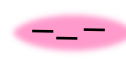

LHAI coupling

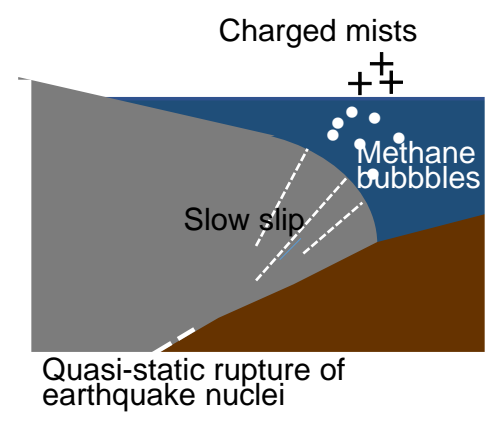

(c) TEC enhancements

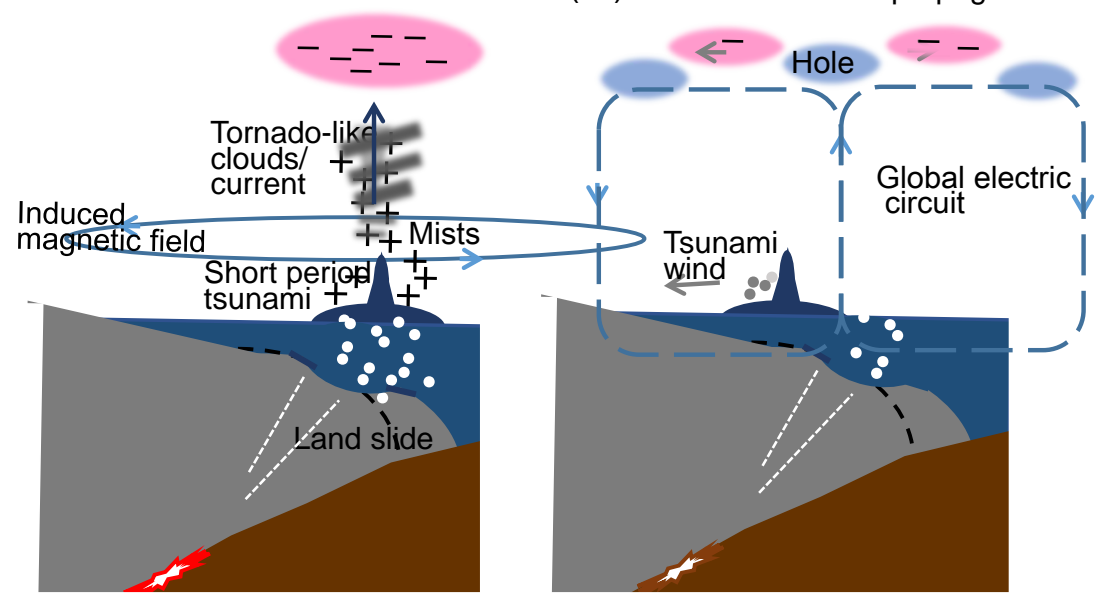

Figure 5. Schematic diagram of the process concerning the anomalous geomagnetic phenomena immediately before and after the 2011 Tohoku-Oki earthquake.

described above starts to become noticeable around approximately 40 minutes before the earthquake, there is a possibility that positively charged mists generated by the Blanchard effect will float in the atmosphere near the sea surface and gradually accumulated. In this case, the LAI coupling models [15] [17], assuming the positive charged ground could be applicable as LHAI coupling for the precursor $\triangle \mathrm{D}$ and VTEC anomalies in the Tohoku-Oki earthquake, although any quantitative explanation of $\Delta \mathrm{D}$ variation still remain to be explained in their models. Confirmable scientific evidence was not available for tornado-like clouds and charged mists that may have occurred near the epicentral area, but supporting photographs for these phenomena associated with 2011 Tohoku-Oki earthquake are available, as shown in Appendix B.

In light of the above discussion, we summarize the proposed process concerning a series of $\triangle \mathrm{D}$ and the TEC anomalies immediately before and after the 
mainshock: a gradual increase in the $\triangle \mathrm{D}$ and TEC signals starting approximately 40 minutes before the 2011 Tohoku-Oki earthquake, followed by the impulsive enhancements that appeared approximately 10 minutes after the earthquake, as shown by the schematic diagrams in Figure 5(a) through Figure 5(d).

\section{Acknowledgements}

The authors would like to thank the Genesis Research Institute, Inc. for financial support and the Geospatial Information Authority (GSI) of Japan, the Japan Meteorological Agency (JMA), the United States Geological Survey (USGS), the Data Analysis Center for Geomagnetism and Space Magnetism, Graduate School of Science, Kyoto University, Remote Sensing Technology Center of Japan (RESTEC), NHK (Japan Broadcasting Corporation) for the GPS data, geomagnetic data, earthquake data, AE index, and DAICH satellite image, and video footage, respectively. We also appreciate Guest Editor, M. Hayakawa for his valuable comments on the manuscript.

\section{Conflicts of Interest}

The authors declare no conflicts of interest regarding the publication of this paper.

\section{References}

[1] Heki, K. (2011) Ionospheric Electron Enhancement Preceding the 2011 Tohoku-Oki Earthquake. Geophysical Research Letters, 38, L17312. https://doi.org/10.1029/2011GL047908

[2] Saito, A., Tsugawa, T., Otsuka, Y., Nishioka, M., Iyemori, T., Matsunuma, M., Saito, S., Chen, C.H., Goi, Y. and Choosakul, N. (2011) Acpistoc Resonance and Plasma Depletion Detected by GPS Total Electron Content Observation after the 2011 off Pacific Coast of Tohoku Earthquake. Earth and Planetary Science Letters, 63, 863-867. https://doi.org/10.5047/eps.2011.06.034

[3] Tsugawa, T., Saito, A., Ohtsuka, Y., Nishioka, M., Maruyama, T., Kato, H., Nagatsuma, F. and Murata, K. (2011) Ionospheric Disturbance Detected by GPS Total Electron Content Observation after the 2011 off the Pacific Coast of Tohoku Earthquake. Earth Planets Space, 63, 875-879. https://doi.org/10.5047/eps.2011.06.035

[4] Kakinami, Y., Kamogawa, M., Tanioka, Y., Watanabe, S. Gusman, A.R., Liu, J.Y., Watanabe, Y. and Mogi, T. (2012) Tsunamigenic Ionsphere Hole. Geophysical Research Letters, 39, L00G27. https://doi.org/10.1029/2011GL050159

[5] Kamogawa, M., Orihara, Y., Tsurudome, C., Tomida, Y., Kanay, T., Ikeda, D., Gusman, A.R., Kakinami, Y., Liu, J.Y. and Toyoda, A. (2016) A Possible Space-Based Tsunami Early Warning System Using Observations of the Tsunami Ionosphere Hole. Scientific Reports, 6, 37989. https://doi.org/10.1038/srep37989

[6] Heki, K. and Enomoto, Y. (2013) Preseismic Ionospheric Electron Enhancements Revisited. Journal of Geophysical Research, 118, 1-9. https://doi.org/10.1002/jgra.50578

[7] Utada, H. and Shimizu, H. (2014) Comment on "Preseismic Ionospheric Electron Enhancements Revisted”. Journal of Geophysical Research: Space Physics, 119, 
6011-6015. https://doi.org/10.1002/2014JA020044

[8] Heki, K. and Enomoto, Y. (2014) Reply to Comment by K. Heki and Y. Enomoto on "Preseismic Ionospheric Electron Enhancement Revisited". Journal of Geophysical Research: Space Physics, 119, 6016-6018. https://doi.org/10.1002/2014JA020223

[9] Wyss, M. (1991) Evaluation of Proposed Earthquake Precursors. American Geophysical Union, Washington DC, Volume 302, 94 p. https://doi.org/10.1029/SP032

[10] Heki, K. and Enomoto, Y. (2015) $\mathrm{M}_{\mathrm{w}}$ Dependence of the Preseismic Ionospheric Electron Enhancements. Journal of Geophysical Research: Space Physics, 120, 7006-7020. https://doi.org/10.1002/2015JA021353

[11] Pulinets, S. and Ouzounov, D. (2011) Lithosphere-Atmosphere-Ionosphere Coupling (LAIC) Model-An Unified Concept for Earthquake Precursors Validation. Journal of Asian Earth Sciences, 41, 371-382. https://doi.org/10.1016/j.jseaes.2010.03.005

[12] Ouzounov, D., Pulinets, S., Romanov, A., Romanov, A., Tsubuly, K., Davidenko, D., Kafatos, M. and Taylor, P. (2011) Atmosphere-Ionosphere Response to the M9 Tohoku Earthquake Revealed by Multi-Instrument Space-Borne and Ground Observations: Preliminary Results. Earthquake Science, 24, 557-564. https://doi.org/10.1007/s11589-011-0817-z

[13] Hayakawa, M., Kasahara, Y., Nakamura, T., Hobara, Y., Rozhnoi, A., Solovieva, M., Molchanov, O.A. and Korepanov, Y.V. (2011) Atmospheric Gravity Waves as a Possible Candidate for Seismo-Ionospheric Perturbations. Journal of Atmospheric Electricity, 31, 129-140. https://doi.org/10.1541/jae.31.129

[14] Enomoto, Y. (2012) Coupled Interaction of Earthquake Nucleation with Deep-Earth Gases: A Possible Mechanism for Seismo-Electromagnetic Phenomena. Geophysical Journal International, 191, 1210-1214. https://doi.org/10.1111/j.1365-246X.2012.05702.x

[15] Kuo, C.L., Lee, L.C. and Huba, J.D. (2014) An Improved Coupling Model for the Lithosphere-Atmosphere-Ionosphere System. Journal of Geophysical Research: Space Physics, 119, 3189-3205. https://doi.org/10.1002/2013JA019392

[16] Freund, F. (2010) Toward a Unified Solid State Theory for Pre-Earthquake Signals. Acta Geophysica, 58, 719-766. https://doi.org/10.2478/s11600-009-0066-x

[17] Kelley, M.C., Swartz, W.S. and Heki, K. (2016) Apparent Ionospheric Total Electron Content Variation Prior to Major Earthquakes Due to Electric Fields Created by Tectonic Stresses. Journal of Geophysical Research, 122, JA023601. https://doi.org/10.1002/2016JA023601

[18] Kumagai, H., Pulido, N., Fukuyama, E. and Aoi, S. (2012) Strong Localized Asperity of the 2011 Tohoku-Oki Earthquake, Japan. Earth Planes Space, 64, 649-654. https://doi.org/10.5047/eps.2012.01.004

[19] Brown, L., Wang, K. and Sun, T. (2015) Static Stress Drop in the Mw9 Tohoku-Oki Earthquake: Heterogeneous Distribution and Low Average Value. Geophysical Research Letters, 42, 10595-10600. https://doi.org/10.1002/2015GL066361

[20] Goddin, O.A. (2004) Air-Sea Interaction and Feasibility of Tsunami Detection in the Open Ocean. Journal of Geophysical Research, 109, C05002. https://doi.org/10.1029/2003JC002030

[21] Rolland, L.M., Longnonnè, P., Astafyeva, E., Kherani, E.A., Kobayashi, N., Mann, M. and Munekane, H. (2011) The Resonant Response of the Ionosphere Imaged After the 2011 off the Pacific Coast of Tohoku Earthquake. Earth Planets Space, 63, 853-857. https://doi.org/10.5047/eps.2011.06.020 
[22] Utada, H., Shimizu, H., Ogawa, T., Maeda, T., Furumura, T., Yamamoto, T., Yamazaki, N., Yoshitake, Y. and Nagamachi, S. (2011) Geomagnetic Field Changes in Response to the 2011 off the Pacific Coast of Tohoku Earthquake and Tsunami. Earth and Planetary Science Letters, 311, 11-27. https://doi.org/10.1016/j.epsl.2011.09.036

[23] Maeda,T., Furumura, T., Sakai, S. and Shinohara, M. (2011) Significant Tsunami Observed at Ocean-Bottom Pressure Gauges during the 2011 off the Pacific Coast of Tohoku Earthquake. Earth Planets Space, 63, 803-808. https://doi.org/10.5047/eps.2011.06.005

[24] Tappin, D., Grilli, S.T., Harris, J.C., Geller, R.J., Masterlark, T., Kirby, J.T., Shi, F., Ma, G., Thingbaijam, K.K.S. and Mai, P.M. (2014) Did Submarine Landslide Contribute to the 2011 Tohoku Tsunami? Marine Geology, 357, 344-361. https://doi.org/10.1016/j.margeo.2014.09.043

[25] Utada, H. (2014) Kyodai tsunami ni tomonau jiba-hendo: English Translation; Magnetic Disturbances Associated with Huge Tsunami. JISIN Journal, No. 58, 21-26. (In Japanese)

[26] Johnston, M.J.S., Mueller, R.J. and Sasai, Y. (1994) Magnetic Field Observations in the Near-Field the 28 June 1992 Mw7.3 Landers, California, Earthquake. Bulletin of the Seismological Society of America, 84, 792-798.

[27] Sasai, Y. (2001) Tectonomagnetic Modelling Based on the Piezomagnetism: A Review. Annals of Geophysics, 44, 361-368.

[28] Mizutani, H. and Ishido, T. (1976) A New Interpretation of Magnetic Field Variation Associated with the Matsushiro Earthquakes. Journal of Geomagnetism and Geoelectricity, 28, 179-188. https://doi.org/10.5636/jgg.28.179

[29] Enomoto, Y., Yamabe, T. and Okumura, N. (2017) Causal Mechanisms of Seismo-EM Phenomena during the 1965-1967 Matsushiro Earthquake Swarm. Scientific Reports, 7, 44774. https://doi.org/10.1038/srep44774

[30] Rycroft, M.J., Israelsson, S. and Price, C. (2000) The Grobal Atmospheric Electric Circuit, Solar Activity and Climate Change. The Journal of Atmospheric and Solar-Terrestrial Physics, 62, 1563-1576. https://doi.org/10.1016/S1364-6826(00)00112-7

[31] Tajima, F. and Kennett, B.L.N.L. (2012) Interlocking of Heterogeneous Plate Coupling and Aftershock Area Expansion Pattern for the 2011 Tohoku Mw9 Earthquake. Geophysical Research Letters, 39, L05307. https://doi.org/10.1029/2011GL050703

[32] Ichihara, H., Hamano, Y., Baba, K. and Kasaya, T. (2013) Tsunami Source of the 2011 Tohoku Earthquake Detected by an Ocean-Bottom Magnetometer. Earth and Planetary Science Letters, 382, 117-124. https://doi.org/10.1016/j.epsl.2013.09.015

[33] Sugioka, H., Hamano, Y., Baba, K., Kasaya, T., Tada, N. and Suetsugu, D. (2014) Tsunami: Ocean Dynamo Generator. Scientific Reports, , 4, 3596. https://doi.org/10.1038/srep03596

[34] JAMSTEC (2011) Photos from the 2011 Tohoku Earthquake Source Area Captured by Deep-Sea Submersible Shinkai 6500. https://www.jamstec.go.jp/e/about/press_release/20110815/

[35] Blanchard, D.C. (1963) The Electrification of the Atmosphere by Particles from Bubbles in the Sea. Progress in Oceanography, 1, 73-202. https://doi.org/10.1016/0079-6611(63)90004-1

[36] Enomoto, Y., Yamabe, T., Sugiura, S. and Kondo, H. (2019) Possible Mechanism for the Tsunami-Related Fires That Occurred at Aonae Harbour on Okushiri Island in 
the 1993 Hokkaido Nansei-Oki Earthquakes. Geosciences, 9, 253.

https://doi.org/10.3390/geosciences 9060253

[37] Enomoto, Y. (2002) A Tornado-Type Cloud Observed on January 9, 1995 Prior to the Kobe Earthquake. In: Hayakawa, M. and Molchanov, O.A., Eds., Seismo Electromagnetics. Lithosphere-Atmosphere-Ionosphere Coupling, TERRAPUB, Tokyo, 267-273.

[38] Kakinuma, T. (2011) Watashi ga mita Ohtsunami: English Translation, The Big Tsunami I Saw, Kahoku-Shinpo.

http://memory.ever.jp/tsunami/shogen_natori.html

[39] Kamiyama, M., Sugito, M., Kuse, M., Schekotov, A. and Hayakawa, M. (2016) On the Precursors to the 2011 Tohoku Earthquake: Crustal Movements and Electromagnetic Signatures. Geomatics Natural Hazards and Risk, 7, 471-492.

https://doi.org/10.1080/19475705.2014.937773 


\section{Appendix A}

We revisit on the argument of for whether the precursor $\Delta \mathrm{D}$ variation is due to ionospheric magnetic storm or due to seismic precursor activity. Utada and Shimizu [7] reported that $\Delta \mathrm{D}$ variations during the precursor period of 5:10-5:46 UT on the day that the 2011 Tohoku-Oki earthquake occurred, referred as the $\Delta \mathrm{D}_{1}$ episode by Utada \& Shimizu [7], were caused by a magnetic storm, because there is a correlation between the latitude dependence of $\Delta D_{1}$ and that of the typical storm-time disturbance $\Delta \mathrm{D}$ during the time period of 21:10-21:30 UT on the same day, referred as $\Delta \mathrm{D}_{4}$, among the observation sites, MMB, AKA, ESA, HAR, OTA, KAK, TTK, and CBI (see Figure 1(a), and three other sites that belong to the Earthquake Research Institute, University of Tokyo (not shown in Figure 1(a)). However, correlation in general does not imply causation [A1]. In fact, $\Delta \mathrm{D}$ showed similar time dependences, i.e., increase with time for both $\Delta \mathrm{D}_{1}$ and $\Delta \mathrm{D}_{4}$, episodes at both $\mathrm{MMB}$ vs $\mathrm{KNY}$ and ESA vs KNY, whereas the geomagnetic inclination $\triangle \mathrm{I}$ showed dissimilar time-dependence in the corresponding episodes at both MMB vs KNY and ESA vs KNY as shown in Figure A1(a). Both episodic variations $\Delta \mathrm{D}_{1}$ and $\Delta \mathrm{D}_{4}$ at $\mathrm{MMB}$ are likely to have been affected by a magnetic storm, as the background natural variability is the highest at $\mathrm{MMB}$ [8].

(a)
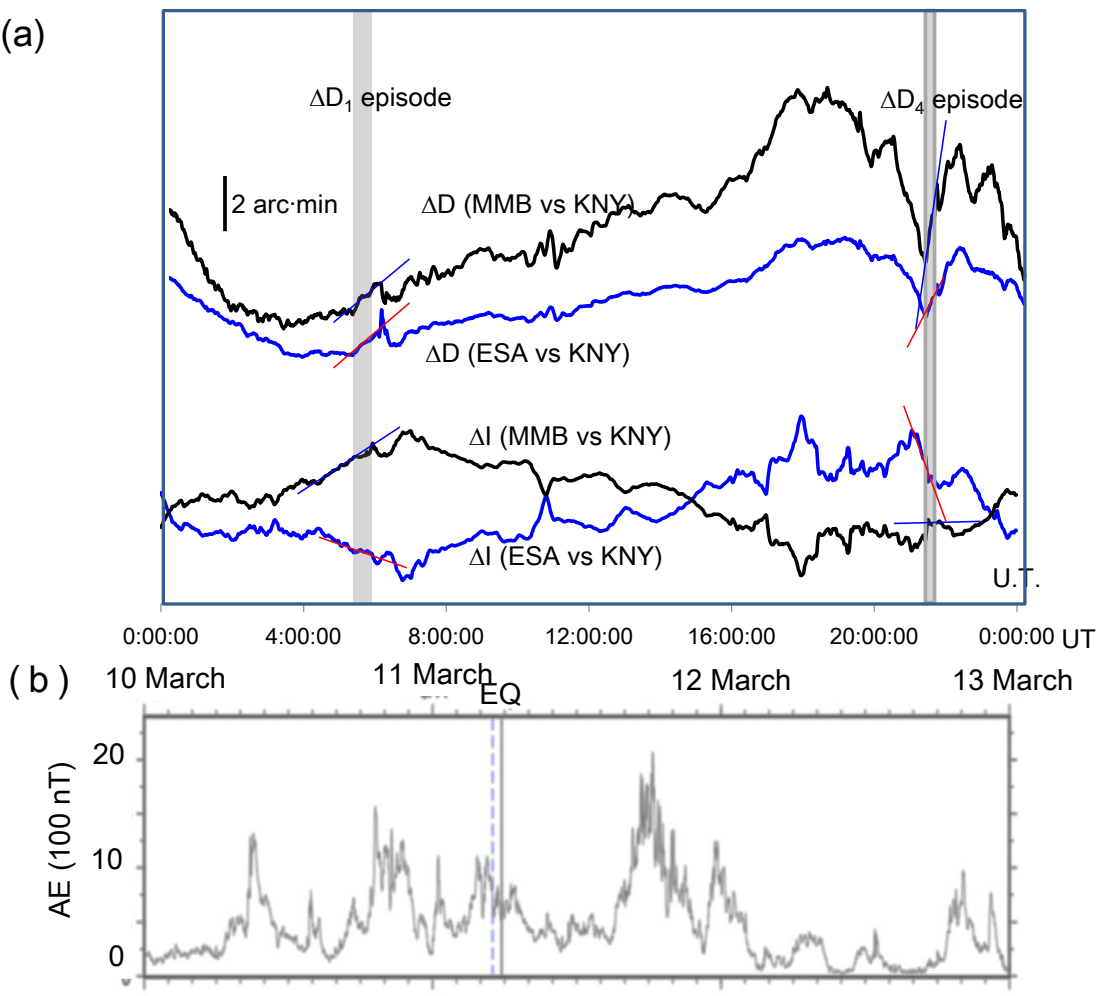

Figure A1. (a) Geomagnetic auroral electrojet (AE) index with a sampling interval of 1 min during 10-12 March 2011 (http://wdc.kugi.kyoto-u.ac.jp/aedir/). (b) $\Delta \mathrm{D}$ and $\Delta \mathrm{I}$ at MMB and ESA as compared to KNY with a sampling interval of 1 min on 11 March 2011. Shadowed areas indicate $\Delta \mathrm{D}_{1}$ (5:10-5:46 UT) and typical storm-time disturbance $\Delta \mathrm{D}_{4}$ (21:10-21:30 UT). 
Furthermore, note that, as shown in the geomagnetic auroral electrojet (AE) index (http://wdc.kugi.kyoto-u.ac.jp/aedir/) 10-12 March 2011 in Figure A1(b), the precursor $\Delta \mathrm{D}_{1}$ episode on the earthquake day (11 March) overlapped less with substorm periods of auroral activities and was rather calm.

The results which indicate positive increases in $\Delta \mathrm{D}_{1}$ are more enhanced as the locations of the observation sites approach the epicentre, indicating that the origin for the precursor $\Delta \mathrm{D}_{1}$ increases should be attributed to electromagnetic activity in the imminent earthquake preparation process generated near the epicentral area.

\section{Reference}

[A1] Altman, N. and Krzywinski, M. (2015) Association, Correlation and Causation. Nature Method, 12, 899-900.

\section{Appendix B}

We describe additional information about the occurrence of mists due to bubble collapse and the generation of tornado-like cloud on the sea as illustrated in Figure 5. On the day of the 2011 Tohoku-Oki earthquake, a whitish bubbled sea surface suddenly appeared off the coast of several kilometres away from Natri City (Figure B1(a) and Figure B1(b)) after NHK TV video imagery from "Kuori tsunami shirarezaru jituzo (in Japanese) which means black tsunami, unknown
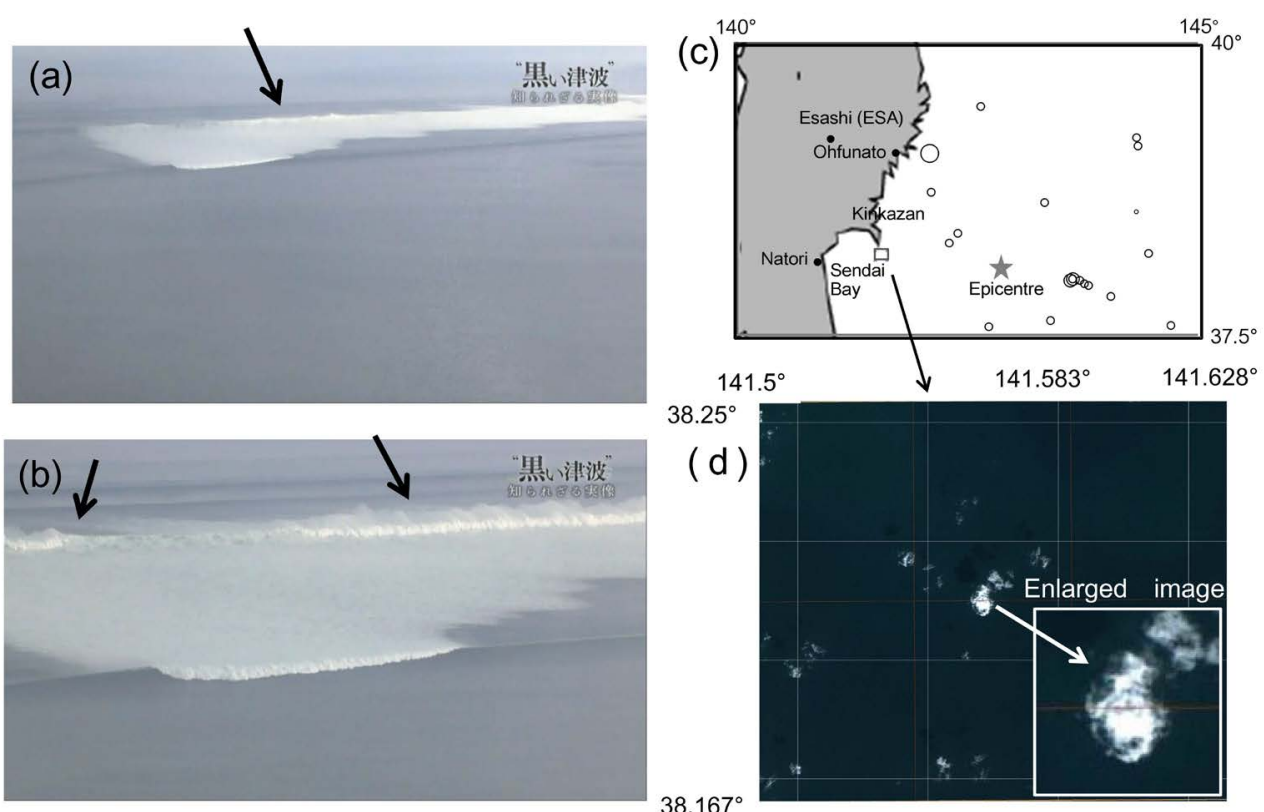

Figure B1. (a) Generation and (b) propagation of whitish-bubbled tsunami water at 7:12 UT on 11 March as photographed in the 2011 Tohoku-Oki earthquake offshore of Sendai Bay, Natori city (see Figure 1(a)). Note that tsunami waters covered by smoke/mists (see arrows) are pushing numerous bubbles as they rush toward the shore. NHK TV video imagery from "Kuroi tsunami shirarezaru jituzo (in Japanese)" (Black tsunami, unknown fact images), which aired on March 3, 2019. (c) (d) A tornado-like cloud captured off the coast of Kinkazan at a squared area ure by ALOS satellite DAICHIure. 
fact images, which aired on 3 March, 2019. The sea level rose violently, and the tsunami, with rising mists, propagated toward the coast, bearing bubbles in the tsunami front, possibly due to the wind enhancement of tsunami-induced perturbations [20].

There was a satellite image of a tornado-like cloud. Around 1:25 UT on 24 March 2011, when the aftershock activities related to the 2011 Tohoku-Oki earthquake was active, the ALOS satellite Daichi observed a tornado-like cloud standing off the coast of Kinkazan as shown in Figure B1(c) and Figure B1(d).

These images are evidence supporting the model that demonstrated the occurrence of the mists and tornado-like clouds that are mentioned in the discussion. 